\title{
Sistem Pakar Identifikasi Kerusakan Motor Matic Beserta Solusi
}

\author{
Sondang Sibuea ${ }^{1}$ \\ Program Studi Teknik Informatikai \\ Universitas Mohammad Husni Thamrin \\ sondsib@gmail.com
}

\author{
Budi Setiawan ${ }^{2}$ \\ Program Studi Teknik Informatika \\ Universitas Mohammad Husni Thamrin
}

\begin{abstract}
Abstrak - ABSTRAK
Semakin hari jumlah kendaraan bermotor makin meningkat. Kendaraan bermotor ada dua jenis yaitu kendaraan bermotor dengan transmisi manual dan dengan transmisi automatis (matic). Sebagian besar masyarakat memilih untuk menggunakan motor jenis matic dikarenakan penggunaannya yang mudah, nyaman dan tidak rumit perawatannya. Namun para pemilik kendaraan roda dua ini, kadang tidak menghiraukan soal perawatan kendaraan miliknya sendiri dikarenakan keterbatasan pengetahuan pemilik kendaraan roda dua tersebut tentang kerusakan yang dialami kendaraannya dan mahalnya biaya perawatan serta suku cadang (spare part) kendaraan tersebut. Dengan adanya sistem ini diharapkan dapat membantu masyarakat untuk dapat mengidentifikasi kerusakan motor matic secara dini, sehingga bisa meminimalisir kerusakan yang ditimbulkan. Aplikasi ini dikembangkan dengan menggunakan bahasa pemrograman PHP dan database MySQL. Metode inferensi yang digunakan adalah forward chaining dimana pelacakan didasarkan atas data atau fakta kemudian menuju pada kesimpulan yaitu jenis kerusakan motor matic dan solusi penanganannya.
\end{abstract}

Kata Kunci :Sistem Pakar, forward chaining, basis pengetahuan

\section{Pendahuluan}

Agar kendaraan motor matic selalu dalam kondisi baik maka kendaraan roda dua tersebut harus selalu dirawat. Karenanya pemilik kendaraan roda dua harus mempunyai pengetahuan tentang perawatan kendaraan miliknya. Walaupun sudah banyak bengkel resmi dan non resmi yang tersedia, tidak menutup kemungkinan pemilik kendaraan tidak cukup mampu dalam merawat dan memperbaikinya, ini dikarenakan semakin mahalnya biaya perawatan serta suku cadang kendaraan roda dua tersebut.

Untuk mengatasi permasalahan tersebut, dalam penelitian ini akan dikembangkan Sistem Pakar yang dapat membantu pemakai kendaraan dalam merawat dan memperbaiki kerusakan kendaraan motor khususnya motor matic.

\section{Konsep Dasar}

Istilah sistem pakar berasal dari istilah knowledge-based expert system. Istilah ini muncul karena untuk memecahkan masalah, sistem pakar menggunakan pengetahuan seorang pakar yang dimasukkan ke dalam komputer. Seseorang yang bukan pakar menggunakan sistem pakar untuk meningkatkan kemempuan pemecahan masalah, sedangkan seorang pakar menggunakan sistem pakar untuk knowledge assistant.

Ada dua bagian penting dari sistem pakar, yaitu lingkungan pengembangan (development environment) dan lingkungan konsultasi (consultation environment).

Lingkungan pengembang digunakan oleh pembuat sistem pakar untuk membangun komponen-komponennya dan memasukan pengetahuan ke dalam knowledge base (basis pengetahuan). Lingkungan konsultasi digunakan oleh pengguna untuk berkonsultasi sehingga pengguna mendapatkan pengetahuan dan nasihat dari sistem pakar layaknya berkonsultasi dengan seorang pakar. 
Pada sistem pakar berbasis rule, domain pengetahuan direpresentasikan dalam sebuah kumpulan rule berbentuk IF-THEN, sedangkan data direpresentasikan dalam sebuah kumpulan fakta-fakta tentang kejadian saat ini. Mesin inferensi membandingkan maing-masing rule yang tersimpan dalam basis pengetahuan dengan fakta-fakta yang terdapat dalam database. Jika bagian IF (kondisi) dari rule cocok dengan fakta, maka rule dieksekusi dan bagian THEN (aksi) diletakkan dalam database sebagai fakta baru yang ditambahkan.

Forward chaining adalah teknik penalaran yang dimulai dengan fakta yang diketahui, kemudian mencocokkan fakta-fakta tersebut dengan bagian IF dari rules IF-THEN. Bila ada fakta yang cocok dengan bagian IF, maka rule tersebut dieksekusi. Bila sebuah rule dieksekusi, maka sebuah fakta baru (bagian THEN) ditambahkan ke dalam database. Setiap kali pencocokan, dimulai dari rule teratas. Setiap rule hanya boleh dieksekusi sekali saja. Proses pencocokan berhenti bila tidak ada lagi rule yang bisa dieksekusi.[1]

Backward chaining adalah metode inferensi yang bekerja mundur ke arah kondisi awal. Proses diawali dari Goal (yang berada dibagian THEN dari rule IF-THEN), kemudian pencarian mulai dijalankan untuk mencocokkan apakah fakta-fakta yang ada cocok dengan premis-premis di bagian IF. Jika cocok, rule dieksekusi, kemudian hipotesis di bagian THEN ditempatkan di basis data sebagai fakta baru. Jika tidak cocok, simpan premis di bagian IF ke dalam stack sebagai subGoal. Proses berakhir jika Goal ditemukan atau tidak ada rule yang bisa membuktikan kebenaran dari subGoal atau Goal.[2]

\section{Metode Penelitian}

Pengumpulan data dilakukan untuk memperoleh beberapa informasi yang berkaitan dalam pembuatan aplikasi sistem pakar identifikasi kerusakan motor matic yaitu berupa data gejala, data kerusakan, dan data hubungan gejala dengan kerusakan dan dengan solusinya. Pengumpulan data digunakan untuk membangun basis pengetahuan dan basis aturan. Data gejala yang digunakan dalam sistem pakar ini berjumlah 125 gejala. Untuk menghasilkan sistem pakar identifikasi kerusakan motor matic yang baik diperlukan pembuatan basis aturan yang lengkap dan baik agar proses inferensi berjalan dengan baik. Basis aturan diambil dari basis pengetahuan yang ada kemudian disusun dalam bentuk aturan (rule).

Dari tabel aturan yang telah didapat, maka dapat terbentuk suatu pohon keputusan. Proses pencarian dari pohon keputusan menggunakan pencarian Best First Search, pencarian diperbolehkan mengunjungi node yang ada di level lebih rendah asalkan node ini memiliki nilai heuristik yang lebih baik. Pohon keputusan terdiri dari gejala, kerusakan dan busur yang menunjukkan hubungan antar objek.

Sistem pakar ini menggunakan metode penalaran forward chaining (pelacakan maju) yaitu dimulai dari sekumpulan gejala-gejala dengan awalan A hingga awalan E, sampai tujuan akhir berupa hasil identifikasi kerusakan motor Yamaha MIO dengan kode awalan K.

Antarmuka (interface) merupakan bagian dari sistem pakar yang digunakan sebagai media atau alat komunikasi antar user dan sistem. Di dalam interface ini di bedakan menjadi dua user yaitu user umum dan user administrator. User umum adalah pengguna yang menggunakan sistem pakar ini untuk mencari informasi dari kerusakan yang dialami oleh kendaraan miliknya. User administrator adalah user yang bertugas untuk melakukan proses pengelolaan data dan perawatan data di dalam sistem pakar jika diperlukan perubahan.

\section{Rancangan Sistem Pakar}

Antarmuka (interface) dari sistem pakar terdiri dari dua mode, yaitu mode konsultasi dan mode pengembangan. Mode konsultasi ditujukan untuk user yang akan berkomunikasi dengan sistem pakar, untuk mengetahui kerusakan kendaraan motor matic beserta 
solusinya. Mode pengembangan ditujukan untuk user admin untuk pengelolaan basis pengetahuan jika diperlukan perubahan pada aturan atau data lainnya.

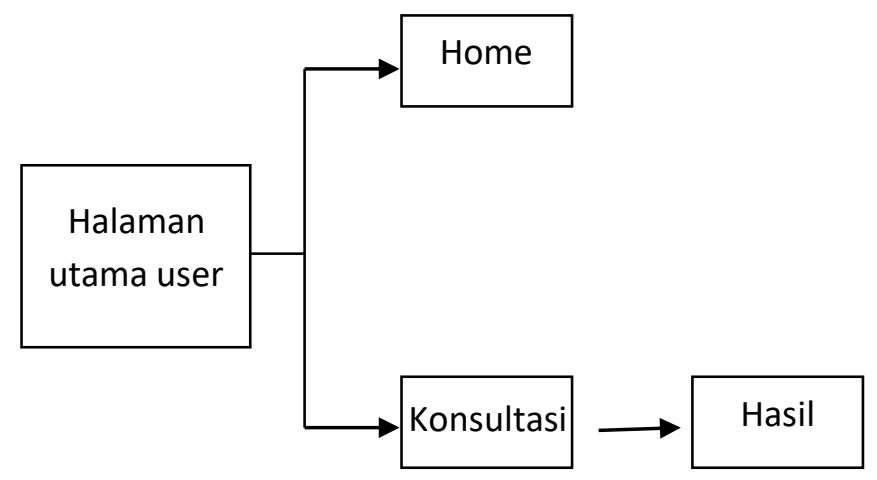

Gambar 1. Interface untuk user

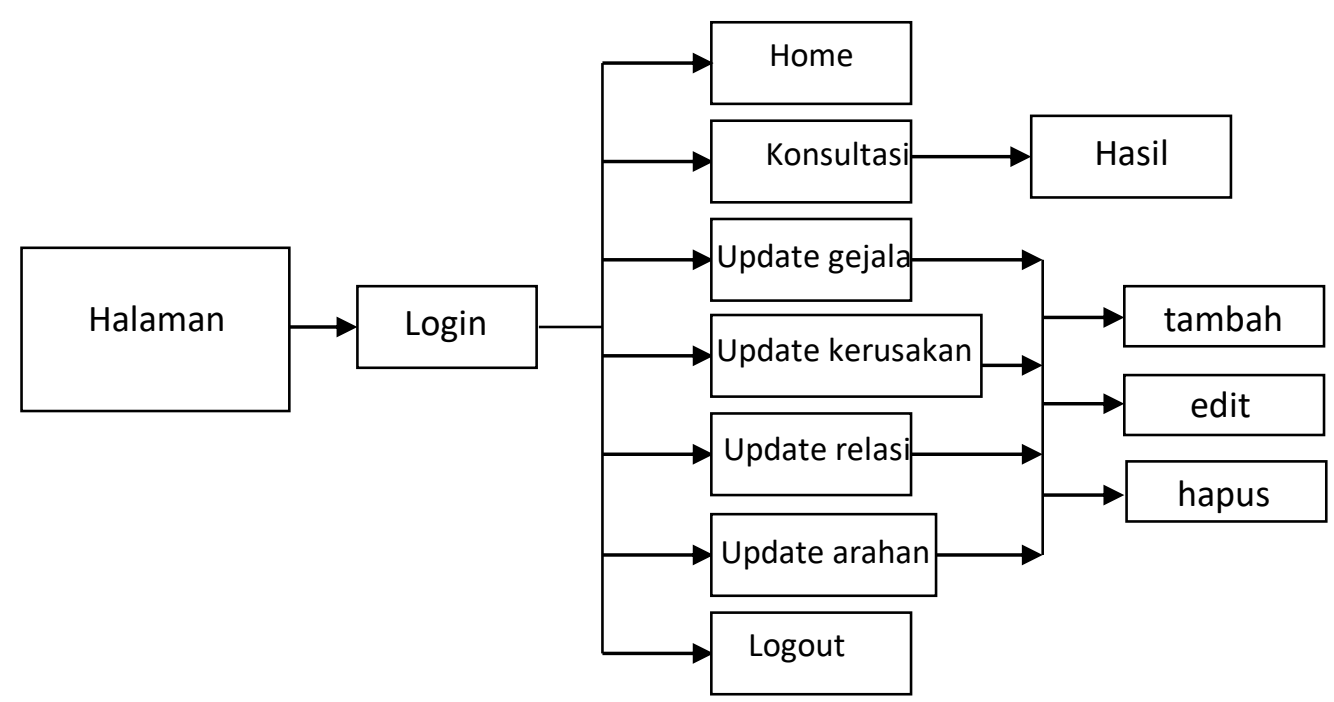

Gambar 2. Interface untuk admin 


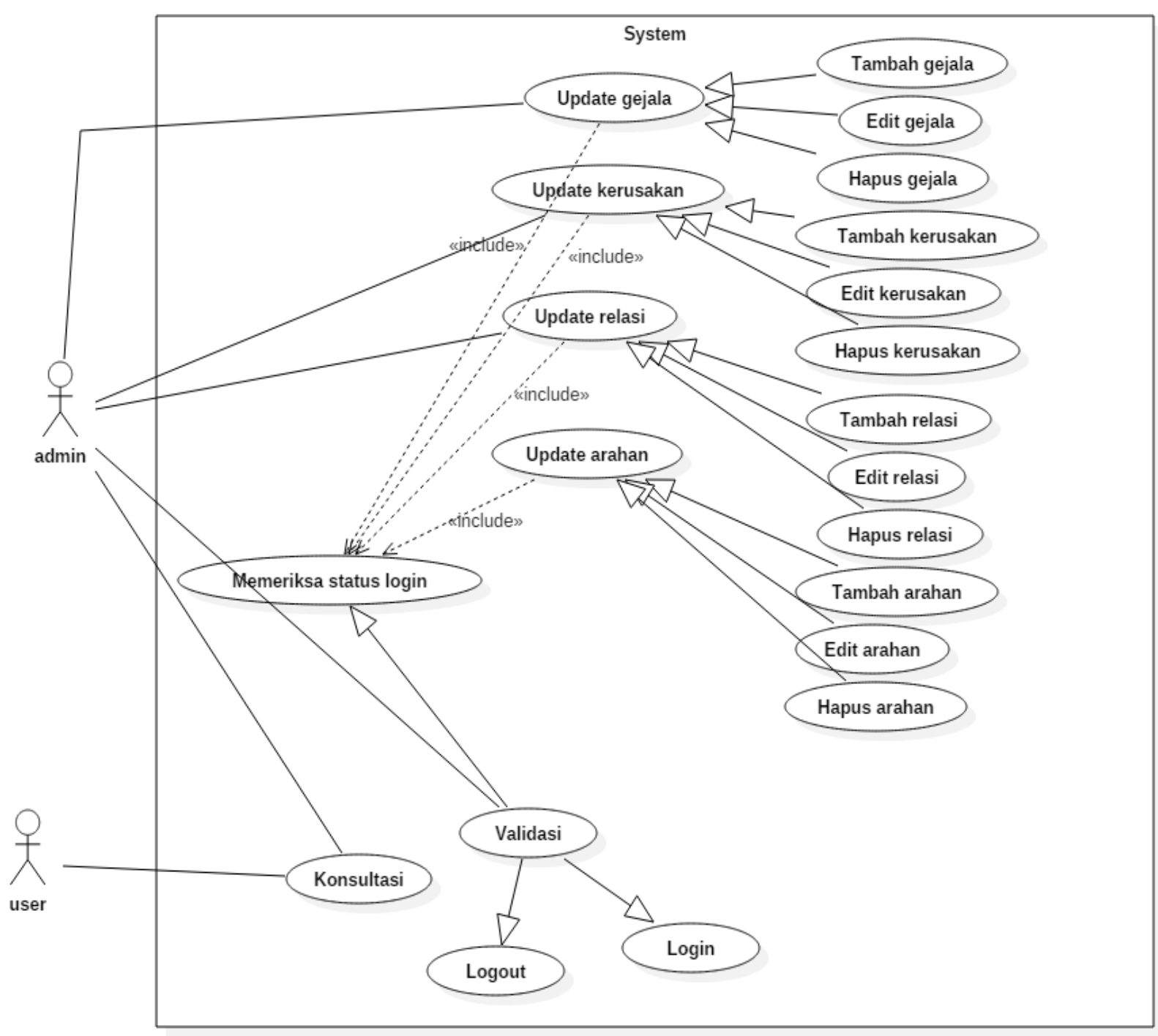

Gambar 3. Diagram use case Sistem Pakar pernyataan gejala yang ada sesuai dengan masalah yang dialami.

\section{Implementasi}

Sistem pakar ini dibuat dengan menggunakan bahasa pemrograman PHP, web server xampp dan aplikasi database MySQL.

Halaman utama ini merupakan halaman awal dari sistem pakar identifikasi kerusakan motor matic. Ada beberapa menu yang dapat dipilih oleh user, yaitu "Home" untuk kembali ke halaman utama, "Konsultasi" untuk melakukan konsultasi, dan "Login" untuk masuk sebagai admin.

Tampilan Layar konsultasi berfungsi sebagai sarana untuk user berkonsultasi tentang masalah kerusakan motor matic. Klik salah satu
Tampilan hasil konsultasi berisikan kerusakan dan solusi setelah user menjawab pernyataanpernyataan gejala yang diajukan. 


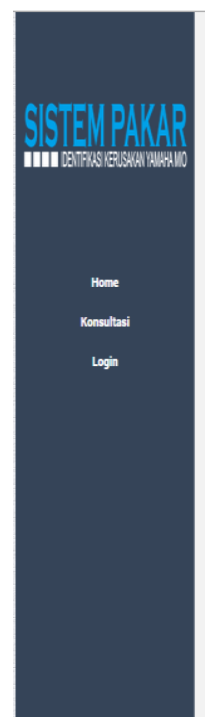

SELAMAT DATANG DI SISTEM PAKAR IDENTIFIKAS KERLSAKAN MOTOR YAMAHA MIIO.

Website sistem palkar ini bertiviuan untuk memberikan kemudahan bage nntuk melalukan proses identifikasi kerusakan caranya culup mudal Gatu user culkup menjarrab pertanyaan-pertanyaan dari sistem berup gejala-gejala yang munnkin dirasakannya. Setelah itu sistem

Gambar 4. Halaman Utama

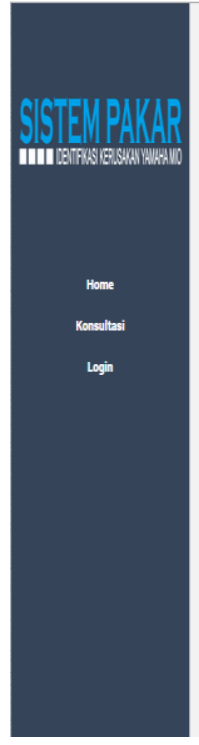

Pertanyaan Identifikasi Kerusakan Yamaha Mio

Apakah Motor tidak dapat dinyalaken?

Apakah Motor dapat dinyalakan?

Tidak tahu

Gambar 5. Halaman Konsultasi

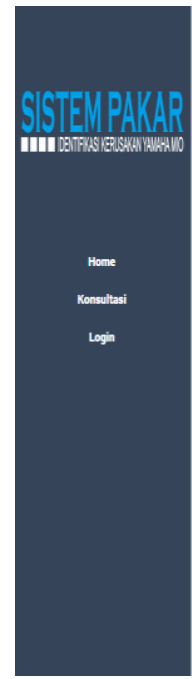

Hasil Identifikasi Kerusakan Yamaha Mio
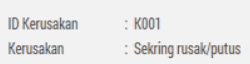

Salusi

nivttan konsultasi lagi?

va

Gambar 6. Halaman Hasil Konsultasi

\section{Kesimpulan}

Sistem pakar yang dibuat ini dapat membantu pemakai dalam mengidentifikasi kerusakan motor matic. Sistem pakar identifikasi kerusakan motor matic ini dibuat menggunakan teknik pelacakan ke depan (forward chaining) dengan penelusuran Best-First Search. Perlu adanya penambahan, memperbaiki serta meningkatkan kualitas dari sistem pakar yang dibuat, karena masih banyak kerusakan yang belum teridentifikasi.

Dalam melakukan proses konsultasi banyak terdapat istilah atau kata-kata asing yang mungkin tidak dipahami oleh pemakai, maka untuk tahap lebih lanjut dibuatkan menu kamus yang dapat mengartikan kata-kata asing tersebut.

\section{REFERENSI}

[1] D. Alfrido and T. K. Gautama, "Sistem Pakar Deteksi Kerusakan Sepeda Motor dengan Metode Forward Chaining," J. Tek. Inform. dan Sist. Inf., 2017.

[2] R. Siregar, "SISTEM PAKAR ANALISA KERUSAKAN PADA SEPEDA MOTOR HONDA BEAT INJECTION DENGAN METODE BACKWARD CHAINING," PETIR, 2018.

[3] B. Setiyaji, T. Susyanto, and D. Remawati, "SISTEM PAKAR DIAGNOSA KERUSAKAN MOTOR 4 TAK HONDA VARIO DENGAN ALGORITMA C4.5," J. Teknol. Inf. dan Komun., 2018.

[4] S. Kosasi, "Pembuatan Aplikasi Diagnosa Kerusakan Mesin Sepeda Motor Matic dengan Case-Based Reasoning," Creat. Inf. Technol. J., 2015.

[5] J. Nasir and Z. H. Gultom, "Sistem Pakar Untuk Mendeteksi Kerusakan Pada Sepeda Motor Dengan Menggunakan Metode Forward 
Chaining Berbasis Web," Digit. Zo. J. Teknol. Inf. dan Komun., 2018.

[6] P. A. Bima and S. Bakhri, "Sistem Pakar Diagnosis Kerusakan Mesin Sepeda Motor Non Injeksi Yamaha Pada Bengkel Dirgantara Motor," Paradigma, 2018.

[7] C. Grosan and A. Abraham, "RuleBased Expert Systems," Intell. Syst. Ref. Libr., 2011. 